\title{
Particulate Matter Emitted from Poultry and Pig Houses: SOURCE IDENTIFICATION AND QUANTIFICATION
}

\author{
M. Cambra-López，T. Hermosilla，H. T. L. Lai，A. J. A. Aarnink， N. W. M. Ogink
}

\begin{abstract}
There is need to identify and quantify the contribution of different sources to airborne particulate matter (PM) emissions from animal houses. To this end, we compared the chemical and morphological characteristics of fine and coarse PM from known sources collected from animal houses with the characteristics of on-farm fine and coarse airborne PM using two methods: classification rules based on decision trees and multiple linear regression. Fourteen different farms corresponding to seven different housing systems for poultry and pigs were sampled during winter. A total of 28 fine and 28 coarse on-farm airborne PM samples were collected, together with a representative sample of each known source per farm (56 known source samples in total). Source contributions were calculated as relative percentage contributions in particle numbers and then estimated in particle mass. Based on particle numbers, results showed that in poultry houses, most on-farm airborne PM originated from feathers (ranging from 4\% to 43\% in fine PM and from $6 \%$ to $35 \%$ in coarse PM) and manure (ranging from $9 \%$ to $85 \%$ in fine PM and from $30 \%$ to $94 \%$ in coarse PM). For pigs, most on-farm airborne PM originated from manure (ranging from $70 \%$ to $98 \%$ in fine PM and from $41 \%$ to $94 \%$ in coarse PM). Based on particle mass, for poultry most on-farm airborne PM still originated from feathers and manure; for pigs, however, most PM originated from skin and manure. Feed had a negligible contribution to on-farm airborne PM compared with other sources. Results presented in this study improve the understanding of sources of PM in different animal housing systems, which may be valuable when choosing optimal PM reduction techniques.
\end{abstract}

Keywords. Animal housing, Dust, Emissions, Source apportionment.

$\mathrm{L}$ arge amounts of particulate matter (PM) are emitted from animal houses, which can compromise animal and human respiratory health (Radon et al., 2001; Zuskin et al., 1995) and the environment as well. The scientific community and stakeholders (farmers and local authorities) are seeking technically feasible and economically viable solutions to reduce these emissions to comply with air quality regulations. Preventing dust release from its source not only reduces emissions from the animal house but improves the indoor climate as well. To develop such reduction techniques, it is necessary to identify and quantify the sources that contribute to PM in animal houses.

A complete assessment can be achieved by quantifying PM contributions from each source according to particle numbers and mass. Knowledge of the relationship between

Submitted for review in July 2010 as manuscript number SE 8658; approved for publication by the Structures \& Environment Division of ASABE in February 2011. Presented at the 2010 ASABE International Symposium on Air Quality and Manure Management for Agriculture as Paper No. 711P0510cd.

The authors are María Cambra-López, ASABE Member Engineer, Research Agricultural Engineer, Institute of Animal Science and Technology, Universidad Politécnica de Valencia, Valencia, Spain; Txomin Hermosilla, Researcher, Geo-Environmental Cartography and Remote Sensing Research Group, Universidad Politécnica de Valencia, Valencia, Spain; and Huong T. L. Lai, Researcher, André J. A. Aarnink, ASABE Member Engineer, Senior Researcher, and Nico W. M. Ogink, Senior Researcher, Wageningen UR Livestock Research, Lelystad, The Netherlands. Corresponding author: María Cambra-López, Institute of Animal Science and Technology, Universidad Politécnica de Valencia, Camino de Vera s.n., 46022 Valencia, Spain; phone: +34-96-387-98-85; fax: +34-96-387-74-39; e-mail: macamlo@upvnet.upv.es. particle number and mass contributions is essential because it gives an insight into particle size and morphology related to different particle types (sources). Moreover, particle size and morphology are related to a particle's aerodynamic behavior, which is closely related to lung deposition mechanisms in the human airways: inertial impaction, sedimentation, interception, and diffusion (Zhang, 2004). Although current European and U.S. regulations set limits to PM concentrations based on mass, a mass-only approach to reduce PM would have very little effect on the number concentrations of smaller particles found in the fine fraction. This fraction contains fine and ultra-fine particles that pose greater risks of adverse health effects because these particles can go beyond the larynx and penetrate into the unciliated respiratory system (CEN, 1993). The control of particles larger than $2.5 \mu \mathrm{m}$ in diameter, however, is also relevant, because these particles can also cause adverse health effects through deposition in the upper respiratory airways. Furthermore, particles larger than $2 \mu \mathrm{m}$ in diameter found in animal houses have been shown to contain high amounts of odorants (Cai et al., 2006) and micro-organisms (Lee et al., 2006). Consequently, both PM number and mass concentrations should be measured to tackle PM pollution related issues within animal houses, to develop reduction techniques, and to assess their effects.

Analytical methods used to characterize PM, such as microscopic analysis, can supply useful but limited data on particle or source chemical composition and morphological characteristics. To further identify and quantify source contributions, source apportionment models can be used. These models are versatile because they can be used in different scenarios (Watson et al., 2002). 
Source apportionment models based on multivariate linear regression permit quantitative source apportionment and can be used to investigate the relationship between the chemical and physical properties of the source and the properties measured at the site. Linear regression is used to estimate the relative contribution of each known source as the linear sum of products of source compositions and source contributions, based on predetermined source profiles (Hopke, 1991). Furthermore, expert systems based on supervised methods can be used to analyze data systematically. An expert system is software that simulates the judgment and behavior of a human with expert knowledge and experience in a particular field (Jensen, 2005). These systems contain a knowledge base with accumulated experience (data) and a set of rules for applying the knowledge base to each particular situation that is described to the program. Expert systems can be applied as knowledge-engineering tools in any field to interpret, predict, diagnose, design, plan, monitor, and control systems (Kim and Hopke, 1988). Moreover, expert systems can be used to develop custom rules in the form of a decision tree based on examples or training samples with known variables and then classify data according to these rules. User-defined rules based on decision trees have been used to sort and classify particles based on large datasets (Hopke, 2008; Hopke and Song, 1997; Kim and Hopke, 1988; Wienke et al., 1995). Based on known source profiles, rules can also sort and classify measured airborne particles into predetermined and selected classes or sources.

Attempts to identify and quantify primary sources of PM in animal houses have been made for pigs and poultry using different approaches (Feddes et al., 1992; Heber et al., 1988; Honey and McQuitty, 1979; Qi et al., 1992), but most of these studies provide limited data from specific production systems related to single animal categories (turkeys, growingfinishing pigs, and caged layers). Therefore, these studies are valuable for identifying the most likely sources present in specific animal production systems, but there is a lack of comparable source contributions for other production systems, between and within animal categories, for different sized-particles. To this end, specific methodologies need to be developed that include statistical methods to calculate source contributions, and measurement protocols to characterize the morphology and composition of PM in different size fractions in animal houses.

Moreover, it is generally accepted that to apply source apportionment models in animal houses, it is necessary to obtain particle chemical characteristics. However, the presence of similar chemical elements in most sources related to animal PM can complicate discrimination among them (Cambra-López et al., 2011). Hence, the use of specific and detailed source profiles based on additional particle characteristics is necessary. Cambra-López et al. (2011) reported that, in addition to chemical data, particle morphological characteristics could add value in source apportionment in animal houses because, in some cases, animal-related PM can be more heterogeneous in size and morphology than in chemical composition. Therefore, chemical-only or combined chemical and morphological particle characteristics can be used to apportion single sources to on-farm airborne PM and improve the knowledge on the quantitative importance of the different PM sources in terms of number and mass contributions.
The objective of this study was to identify and quantify the contribution of different sources to primary fine $\left(\mathrm{PM}_{2.5}\right)$ and coarse ( $\left.\mathrm{PM}_{10-2.5}\right) \mathrm{PM}$ emissions from animal houses based on chemical and morphological characteristics of particles. A comprehensive list of animal categories was surveyed, including seven different housing systems: broilers on bedding, laying hens on floor, laying hens in aviary, turkeys on bedding, piglets, growing-finishing pigs, and dry and pregnant sows on slatted floor. The relative contribution from each source to PM was estimated in terms of number and mass by comparing the chemical and morphological characteristics of fine and coarse PM from each source with the characteristics of fine and coarse airborne PM from the animal houses. Two methods were used to estimate source contributions: classification rules based on decision trees and multiple linear regression. This study provides a better understanding of sources of PM, which is essential to improve reduction programs applicable to animal houses. It also gives an insight into the environmental hazards of PM and their potential health effects by providing knowledge on sources of PM through properties such as particle morphology and chemical composition.

\section{MATerial AND Methods}

To identify and quantify the contribution of different sources to fine and coarse PM emissions from different housing systems for poultry and pigs, we sampled airborne fine and coarse PM on-farm and collected samples from known potential PM sources.

\section{Housing AND ANIMALS}

Table 1 lists the surveyed animal species, type of housing system, ventilation system, number of animals, and animal age where airborne and source samples were collected. Two different farm locations were sampled for each animal housing system in The Netherlands during winter season. All surveyed animal houses used automatically distributed feeding systems with crumbs or pelleted feed. Broilers and turkey houses used new wood shavings as bedding.

Table 1. Description of surveyed animal houses.

\begin{tabular}{lcccc}
\hline \multicolumn{4}{c}{ Table 1. Description of Surveyed animal houses. } \\
Housing System & $\begin{array}{c}\text { Farm } \\
\text { Location }\end{array}$ & $\begin{array}{c}\text { Vent } \\
\text { System }\end{array}$ & $\begin{array}{c}\text { No. of } \\
\text { Animals }\end{array}$ & $\begin{array}{c}\text { Age } \\
\text { (weeks) }\end{array}$ \\
\hline $\begin{array}{l}\text { Poultry } \\
\text { Broilers, bedding }\end{array}$ & 1 & Tunnel & 50,400 & 4 \\
& 2 & Roof & 2675 & 3 \\
\hline Laying hens, floor & 1 & Tunnel & 3850 & 71 \\
& 2 & Tunnel & 16,500 & 22 \\
\hline Laying hens, aviary & 1 & Tunnel & 24,712 & 71 \\
& 2 & Tunnel & 35,000 & 50 \\
\hline Turkeys, bedding & 1 & Ridge & 5,000 & 12 \\
& 2 & Ridge & 4,040 & 10 \\
\hline Pigs & & & & \\
Piglets, slatted floor & 1 & Roof & 125 & 8 \\
& 2 & Roof & 75 & 9 \\
\hline Growing-finishing pigs, & 1 & Roof & 120 & 16 \\
$\quad$ partially slatted floor & 2 & Roof & 60 & 20 \\
\hline Dry and pregnant sows, & 1 & Roof & 39 & Diverse \\
group housing & 2 & Roof & 46 & Diverse \\
\hline
\end{tabular}




\section{On-FARm Airborne AND Source SAMPLeS}

Virtual cascade impactors (RespiCon, Helmut Hund $\mathrm{GmbH}$, Wetzlar, Germany) were used on each farm to sample airborne fine and coarse PM onto separate polycarbonate filters ( $37 \mathrm{~mm}$ dia., $5 \mu \mathrm{m}$ pore size). This device is a two-stage virtual impactor that follows the convention of the European Standard (CEN, 1993) with a 50\% cutoff at an aerodynamic diameter of $2.5 \mu \mathrm{m}$ (for fine PM) and $10 \mu \mathrm{m}$ (for coarse PM). According to Li et al. (2000), it exhibits differences less than $17 \%$ between measured efficiencies and the curves following the European Standard (CEN, 1993). Virtual impactors are similar to conventional impactors, but the impaction surface is replaced with a virtual space of stagnant or slow-moving air, consequently reducing sampling problems common to conventional impactors, such as overloading and particle bounce losses. Portable pumps (Genie VSS5, Buck, Inc., Orlando, Fla.) were used to draw air through each virtual cascade impactor at a constant flow of $3.11 \mathrm{~L} \mathrm{~min}^{-1}$.

Sampling was conducted during morning (from 09:00 to 12:00) at each animal house. Duplicate airborne fine and coarse PM samples were collected simultaneously near the exhaust. For all the surveyed animal houses, a total of 28 fine and 28 coarse on-farm airborne PM samples were collected indoors. Sampling time varied from 5 to $60 \mathrm{~min}$, adjusted to obtain particle loads of 5 to $20 \mu \mathrm{g}$ particles $\mathrm{cm}^{-2}$ filter, to minimize particle overlap (Willis et al., 2002). One background (outside) sample was taken from 10 to $15 \mathrm{~m}$ upwind of each farm in the same way as indoor samples. Sampling time outside varied from 30 to $60 \mathrm{~min}$.

Additionally, a light-scattering system (DustTrak aerosol monitor, model 8520, TSI, Inc., Shoreview, Minn.) was used for on-line continuous airborne $\mathrm{PM}_{10}$ concentration measurement inside and outside on each farm. Sampling time was 30 to $60 \mathrm{~min}$. One-minute values were recorded and stored. Temperature and relative humidity were also recorded during each sampling, both inside and outside the animal house, using temperature and relative humidity sensors (iLog data logger, Escort Data Loggers, Inc., Buchanan, Va.).

For source samples, composite samples of potential PM sources were collected per source and farm by randomly sampling different locations in the animal house. Besides 14 background samples, a total of 42 known source samples were sampled, including: concentrate feed (all farms), manure (fresh excreta in poultry and fresh feces in pigs), feathers (in poultry), and wood shavings used as bedding material (present only for broilers and turkeys). We also collected skin samples in pig houses, but only from sows because it was impractical to collect such samples from younger animals (piglets and growing-finishing pigs) whose skin was not as loose as a sow's dandruff. However, we used the skin collected from the sows as a representative example of "skin source" in the other pig categories. Approximately 200 to $500 \mathrm{~g}$ of representative samples of feed, manure, and clean wood shavings were collected per farm. For feathers and skin, 10 to $50 \mathrm{~g}$ samples were collected. All samples were stored in clean poly-ethylene bags.

Each source sample per farm was dried for $12 \mathrm{~h}$ at $70^{\circ} \mathrm{C}$ and then crushed in a ball mill for $1.5 \mathrm{~min}$ at $250 \mathrm{rpm}$. Dried and milled samples were stored at room temperature, and then airborne PM was generated in a laboratory dust generator to collect airborne fine and coarse PM samples from each source. The dust generator consisted of a stainless steel cylinder of $20 \mathrm{~cm}$ diameter and $30 \mathrm{~cm}$ height with an airtight lid, which had a mechanical agitation system with rotary blades. A varying quantity, from $0.2 \mathrm{~g}$ (feathers) to $40 \mathrm{~g}$ (feed), of each milled source per farm was introduced in the dust generator and agitated at $200 \mathrm{rpm}$. The generated PM was collected using a virtual cascade impactor (RespiCon, Helmut Hund GmbH, Wetzlar, Germany) with polycarbonate filters ( $37 \mathrm{~mm}$ dia., $5 \mu \mathrm{m}$ pore size), which was placed inside the generator. A portable pump (Genie VSS5, Buck, Inc., Orlando, Fla.) was used to draw air through the impactor from the dust generator. A detailed description of the dust generation process and setup can be found in Cambra-López et al. (2011).

Sampling time during dust generation varied from $1 \mathrm{~min}$ to $7 \mathrm{~h}$, depending on the amount of particles generated, aiming at particle loads of 5 to $20 \mu \mathrm{g}$ particles $\mathrm{cm}^{-2}$ filter (Willis et al., 2002). This generation procedure simulated the process by which PM can be generated in animal houses. According to Gill et al. (2006), generating, collecting, and measuring PM in a controlled laboratory setting is a useful tool for determining the emission potential per mass of source, as well as the physical, morphological, and chemical characteristics of the emission. The laboratory dust generation procedure used in our study worked by generating a large cloud of particles and then collecting a small amount of them. The filter samples generated in the laboratory (46 fine and 46 coarse PM samples) were stored at room temperature $\left(20^{\circ} \mathrm{C}\right.$ to $\left.25^{\circ} \mathrm{C}\right)$ for several months before analysis, in sealed filter cassettes (Omega Specialty Instrument Co., Houston, Tex.). The filter cassettes had a static-dissipative nature and were chosen to protect filters, minimize sample losses, and avoid contamination during storage. Freezing of filters was avoided to prevent physical changes, such as particle fragmentation, during freezing.

\section{Morpho-Chemical Analysis of Airborne And Source SAMPLES}

High-resolution scanning electron microscopy (SEM) (JSM-5410, JEOL Ltd., Tokyo, Japan) combined with energy-dispersive $\mathrm{X}$-ray analysis (EDX) (Link Tetra analyzer, Oxford Instruments, Abingdon, U.K.) was used to obtain particle-by-particle chemical and morphological data. A small section (approximately $1 \mathrm{~cm}^{2}$ ) of the as-collected polycarbonate filter from fine and coarse fractions was cut and mounted on a $12 \mathrm{~mm}$ carbon stub with double-sided carbon adhesive tape. Samples were then coated with carbon using a vacuum evaporator to provide electrical conductivity and create a conductive coating for exposure to the SEM electron beam. Detection of elements with atomic number $\geq 6$ (carbon) was obtained from element $\mathrm{x}$-ray spectra.

The SEM-EDX was conducted manually and operated under the same conditions throughout the study: $10 \mathrm{keV}$ accelerating voltage, $15 \mathrm{~mm}$ working distance, $3 \mathrm{nA}$ electron probe current, $1000 \times$ magnification for coarse $\mathrm{PM}$ and $1800 \times$ for fine $\mathrm{PM}$, and $\mathrm{x}$-ray acquisition time of $60 \mathrm{~s}$ per particle. Secondary electron mode was used for particle location, measurement, analysis, and image acquisition.

At least three fields of view (spots) per filter sample were analyzed. On each analyzed field, both an image (photomicrograph at $1000 \times$ or $1800 \times$, saved in tiff format $1024 \times 768$ resolution) and the single-particle $\mathrm{x}$-ray spectra of every particle found in that field were obtained and stored. Within each field, the minimum projected area diameter for 
the coarse particles was set at $1 \mu \mathrm{m}$. The minimum projected area diameter for the fine particles was set at $0.1 \mu \mathrm{m}$ (Conner et al., 2001). Since the particles were not flat but included complex sizes and shapes, the SEM electron beam and beam energy could be affected by particle morphology. Therefore, these size limits were set to minimize the amount of data acquired for non-particle features (e.g., filter substrate) at the magnifications used. For each airborne sample, a total of 50 to 75 particles were chemically analyzed in each duplicate sample. For each source sample, a total of 25 to 50 particles were chemically analyzed. All x-ray spectra were processed with INCA software (Oxford Instruments, Abingdon, U.K.), confirmed manually to correct for element omission or confusion, and checked to eliminate the contribution of the filter material (carbon and oxygen). In fact, in this study, hair source was not included in the analysis because it showed very high carbon and oxygen peaks in the SEM-EDX, which was confused with the background filter composition.

The stored images (SEM photomicrographs of each field of view) were analyzed using the object-based image analysis (OBIA) approach (Blaschke, 2010) using FETEX 2.0 software (Ruiz et al., 2011). All images were radiometrically corrected by background values to avoid spectral differences due to acquisition conditions and to equalize the background value to compare intensity values between images. Individual particles were defined by means of segmentation using thresholding. The OBIA software extracted spectral, textural, and shape-based features for each detected particle (object).

Therefore, based on chemistry, each particle was characterized by 25 elements: nitrogen $(\mathrm{N})$, sodium $(\mathrm{Na})$, magnesium (Mg), aluminum ( $\mathrm{Al})$, silicon $(\mathrm{Si})$, phosphorus $(\mathrm{P})$, sulfur $(\mathrm{S})$, chlorine $(\mathrm{Cl})$, potassium $(\mathrm{K})$, calcium $(\mathrm{Ca})$, iron $(\mathrm{Fe})$, nickel $(\mathrm{Ni})$, copper $(\mathrm{Cu})$, zinc $(\mathrm{Zn})$, silver $(\mathrm{Ag})$, lead $(\mathrm{Pb})$, tin $(\mathrm{Sn})$, chromium $(\mathrm{Cr})$, cobalt $(\mathrm{Co})$, barium $(\mathrm{Ba})$, bromide $(\mathrm{Br})$, titanium $(\mathrm{Ti})$, vanadium $(\mathrm{V})$, antimony $(\mathrm{Sb})$, and gold $(\mathrm{Au})$. Based on morphological characteristics, each particle was characterized by 23 variables. In total, each particle was exhaustively characterized by 48 variables.

\section{Source Apportionment Methods}

Fine and coarse source samples as well as on-farm airborne fine and coarse PM samples from each animal house were used in source apportionment using classification rules based on decision trees and multiple linear regression. Single-particle chemical and morphological characteristics obtained using SEM-EDX were used as data sources. Apportionment results were calculated as relative percentage contributions in number and then estimated in terms of mass. Results provided by the two methods are compared and discussed.

\section{Classification Rules Based on Decision Trees}

Decision trees were used to develop a set of rules for each group of sources from each animal house. Single-particle chemical and morphological characteristics from known sources obtained using SEM-EDX were joined in a combined database and used in this process. Decision trees were built using See 5 software, using the C5.0 classification algorithm, which is the latest version of the algorithms ID3 and C4.5 developed by Quinlan (1993). Decision trees were created following the boosting multiclassifier method (Freund, 1995). This method searched the features that best separated one source from the other by dividing data using mutually exclusive conditions until the newly generated subgroups were homogeneous, i.e., all the elements in a subgroup belonged to the same class or a stopping condition was fulfilled. The rules developed using the known sources were then applied to classify the airborne on-farm samples into one of the known sources based on their chemical and morphological characteristics.

Accuracy of this method was predicted through leaveone-out cross-validation using a single observation from the source samples as validation data and the remaining observations as training data. The cross-validation statistical method worked by applying the rules to the source samples and comparing the source assigned to each particle using the rules with its reference source per farm. Overall measure of prediction accuracy for number of particles was obtained by dividing the total correct validations in each source by the total number of classified particles.

\section{Multiple Linear Regression}

Multiple linear regression was also used to apportion airborne PM sampled on the farms to the known sources. Bulk source chemical characteristics from known sources obtained from the average of single-particle chemical characteristics using SEM-EDX, were used in this process. The average PM concentration of elements in fine and coarse airborne on-farm samples were used as dependent variables, and the average fine and coarse PM concentrations of elements in each source were used as independent variables. All elements were included at once in the model using Genstat (Genstat Committee, 2008) following equation 1:

$$
Y_{i m}=\sum_{k=1}^{n}\left(f_{i k m} \times F_{i k m}\right)
$$

where

$$
\begin{aligned}
Y_{i m}= & \text { relative concentration of the } i \text { th element in } \\
& \text { collected airborne fine or coarse PM on the } m \text { th } \\
& \text { farm (average of duplicate samples) } \\
f_{i k m}= & \text { number contribution of the } i \text { th element of the } k \text { th } \\
& \text { source to airborne fine or coarse PM on the } m \text { th } \\
& \text { farm (the sum of the fractions was set to } 1) \\
F_{i k m}= & \text { average relative concentration of the } i \text { th element in } \\
& \text { the } k \text { th source on the } m \text { th farm. }
\end{aligned}
$$

\section{Mass Estimation}

Results from the classification rules based on decision trees and multiple linear regression were given in particle numbers. Particle number contributions were transformed into mass contributions based on the average mass of particles in each source. The mass for each single particle $(m)$ was calculated from the projected area diameter $\left(D_{p}\right)$ provided by the SEM images, based on a density value and shape factor, following the equation for the mass of a particle (eq. 2) (Ott et al., 2008). From single-particle masses, the average particle mass per source was calculated:

$$
m=\rho_{p} \times v_{p}=\rho_{p} \times\left(\frac{4}{3} \pi r^{3}\right)=\frac{\rho_{p} \times \pi\left(\frac{D_{p}}{S_{v}}\right)^{3}}{6}
$$


where

$m=$ particle mass

$\rho_{p}=$ particle density

$v_{p}=$ particle volume

$r=$ equivalent radius of a spherical particle

$D_{p}=$ projected area diameter, $D_{p}=2 \times \sqrt{\frac{\text { Area }}{\pi}}$

$S_{v}=$ volume shape factor, a correction factor to convert $D_{p}$ to equivalent volume diameter, defined as the diameter of a sphere having the same volume as the irregular particle.

We assumed average values for density of $1.2 \mathrm{~g} \mathrm{~cm}^{-3}$ (feathers), $2.6 \mathrm{~g} \mathrm{~cm}^{-3}$ (feed), $1.3 \mathrm{~g} \mathrm{~cm}^{-3}$ (hair), $1.5 \mathrm{~g} \mathrm{~cm}^{-3}$ (manure and wood shavings), $1.4 \mathrm{~g} \mathrm{~cm}^{-3}$ (skin), and $2.1 \mathrm{~g}$ $\mathrm{cm}^{-3}$ (outside) (McCrone, 1992). Shape factors used in the mass calculation were obtained from Zhang (2004), assigning values of 1.06 (feathers and wood shavings), 1.08 (feed and outside), 1.15 (poultry manure), 1.36 (pig manure), and 1.88 (skin).

\section{RESULTS}

\section{On Farm Airborne PM Measurements}

Environmental conditions during sampling are shown in table 2, including average $\mathrm{PM}_{10}$ concentrations measured using a light-scattering system, relative humidity, and temperature measured inside and outside the animal houses. Values in the table represent sampling time averages over 5 to $60 \mathrm{~min}$ and standard errors between the two surveyed houses for the same animal category.

\section{SOURCE IDENTIFICATION}

Sources were identified through individual particle morphologies based on SEM observations. Different types of particles collected from different animal housing systems were identified by comparison to known standards (McCrone, 1992; Cambra-López et al., 2011). Figure 1 shows examples of particle types from different animal housing systems. In broiler houses, a mixture of bent, soft, and loose particles probably from feathers, and flattened agglomerates is shown in figure 1a. Bent, sharp-edged particles from wood shavings and spherical particles from excreta (sometimes agglomerated) could also be identified (fig. 1a). For laying hens, spherical particles from excreta were dominant in collected PM in floor housing systems (fig. 1b) and also in aviary systems (fig. 1c). In turkey houses, bent, sharp-edged particles from wood shavings or feathers, and few spherical particles from excreta were identified (fig. 1d). In piglet houses, deposited round gray, smooth particles were identified, together with some brighter layered manure particles (fig. 1e). A mixture of layered manure particles and large, flattened skin particles was identified in collected PM from piglet houses (fig. 1f) and from growing-finishing pigs (fig. 1g). Large, folded skin particles were identified in collected PM from dry and pregnant sow houses (fig. 1h).

\section{Contribution of Sources to On-Farm Airborne PM EXPRESSED IN NUMBER}

Source apportionment using classification rules based on decision trees and multiple linear regression resulted in relative percentage contributions of sources to on-farm airborne PM expressed in particle numbers. A total of 912 individual particles were apportioned in fine and 1071 in coarse PM using classification rules based on decision trees. A total of 1546 individual particles were apportioned in fine and 1670 in coarse PM using multiple linear regression.

\section{Using Classification Rules Based on Decision Trees}

Results using classification rules based on decision trees are shown in table 3 (fine PM) and table 4 (coarse PM), together with method accuracies. Results indicated that for poultry, most of the PM originated from feathers and manure. The relative percentage contribution of manure was generally higher in coarse PM (ranging from $30 \%$ to $87 \%$ ) compared with fine PM (ranging from 9\% to 85\%). Even though the number of sources was not equal among poultry categories due to the presence of wood shavings for broilers and turkeys and not for laying hens, the relative percentage contributions of manure were generally higher for laying hens compared with broilers and turkeys; whereas feather contribution was higher for broilers and turkeys compared with laying hens. Where present, wood shavings contributed less than $20 \%$ of particle numbers. For pigs, most of the PM originated from manure. The relative percentage contribution of manure was higher in fine PM (ranging from $70 \%$ to $89 \%$ ) compared with coarse PM (ranging from $41 \%$ to $84 \%$ ) for all pig categories. Skin and feed were the other most important contributing sources for pigs. The relative percentage contribution of skin varied from $2 \%$ to $33 \%$, varying between pig categories, being generally higher in coarse PM compared with fine PM. The relative percentage contribution of feed was found at or below $16 \%$ for all animal categories. It was slightly higher for pigs compared with poultry, being the highest for piglets, in both fine and coarse PM. Outside particles had a relevant contribution for broilers and turkeys, especially in fine PM.

Table 2. Summary of average $P M_{10}$ measurements, temperature ( $T$ ) and relative humidity $(\mathrm{RH})$ inside and outside the surveyed animal houses. Standard error (SE) represents variation between both surveyed animal houses for the same animal category. ${ }^{[a]}$

\begin{tabular}{|c|c|c|c|c|c|c|c|c|c|c|c|c|}
\hline \multirow[b]{2}{*}{ Animal Category } & \multicolumn{2}{|c|}{$\begin{array}{c}\mathrm{PM}_{10} \text { Inside } \\
\left(\mathrm{mg} \mathrm{m}^{-3}\right)\end{array}$} & \multicolumn{2}{|c|}{$\begin{array}{c}\mathrm{PM}_{10} \text { Outside } \\
\left(\mathrm{mg} \mathrm{m}^{-3}\right)\end{array}$} & \multicolumn{2}{|c|}{$\begin{array}{c}T \text { Inside } \\
\left({ }^{\circ} \mathrm{C}\right)\end{array}$} & \multicolumn{2}{|c|}{$\begin{array}{c}\text { RH Inside } \\
(\%)\end{array}$} & \multicolumn{2}{|c|}{$\begin{array}{c}T \text { Outside } \\
\left({ }^{\circ} \mathrm{C}\right)\end{array}$} & \multicolumn{2}{|c|}{$\begin{array}{c}\text { RH Outside } \\
(\%)\end{array}$} \\
\hline & Avg. & $\mathrm{SE}$ & Avg. & SE & Avg. & $\mathrm{SE}$ & Avg. & SE & Avg. & SE & Avg. & $\mathrm{SE}$ \\
\hline Broilers & 1.96 & 0.55 & 0.08 & 0.05 & 23.2 & ND & 81.6 & ND & 13.2 & ND & 50.6 & ND \\
\hline Laying hens, floor & 3.94 & 0.69 & 0.03 & 0.00 & 16.2 & 1.7 & 74.8 & 0.5 & 10.3 & 0.4 & 74.4 & 18.8 \\
\hline Laying hens, aviary & 3.06 & 1.54 & 0.03 & 0.00 & 15.6 & 3.2 & 70.4 & 3.2 & 10.3 & 0.4 & 74.4 & 18.8 \\
\hline Turkeys & 2.32 & 0.99 & 0.08 & 0.05 & 19.4 & 2.5 & 63.3 & 7.0 & 11.3 & 0.1 & 54.3 & 0.2 \\
\hline Piglets & 1.44 & 0.11 & 0.03 & 0.01 & 25.2 & 0.1 & 75.8 & 0.3 & 11.4 & 1.8 & 55.0 & 20.5 \\
\hline Growing-finishing pigs & 1.27 & 0.35 & 0.03 & 0.01 & 21.9 & 0.8 & 62.3 & 9.0 & 11.4 & 1.8 & 55.0 & 20.5 \\
\hline Dry and pregnant sows & 0.39 & 0.01 & 0.03 & 0.01 & 23.9 & ND & 75.6 & ND & 13.3 & ND & 34.5 & ND \\
\hline
\end{tabular}

[a] $\mathrm{ND}=$ no data due to equipment failure in one of the farms. 


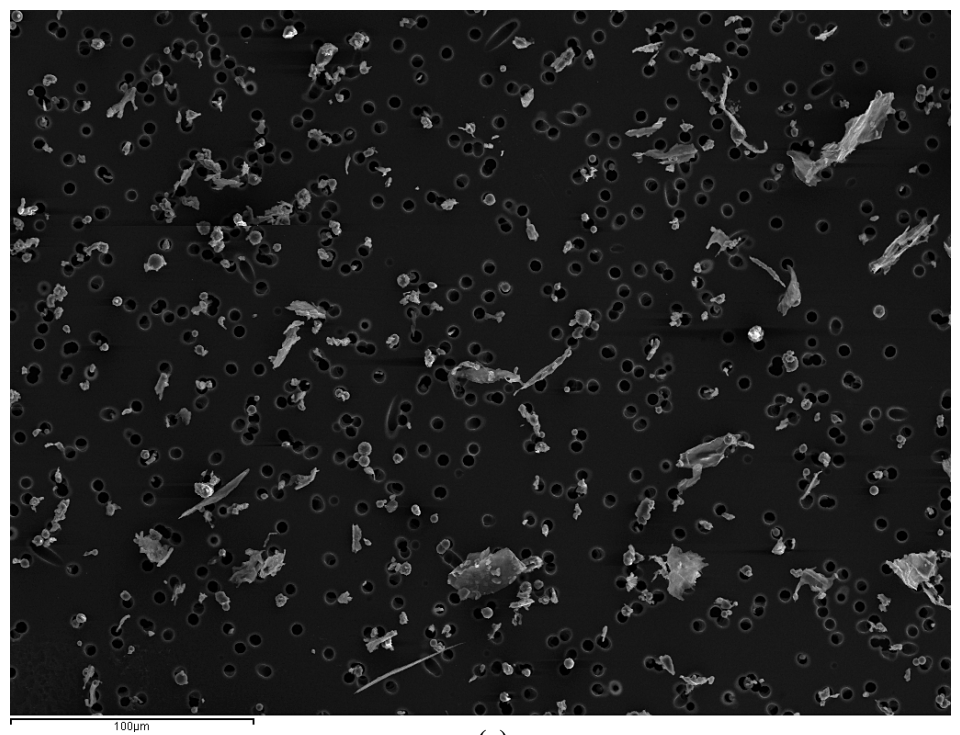

(a)

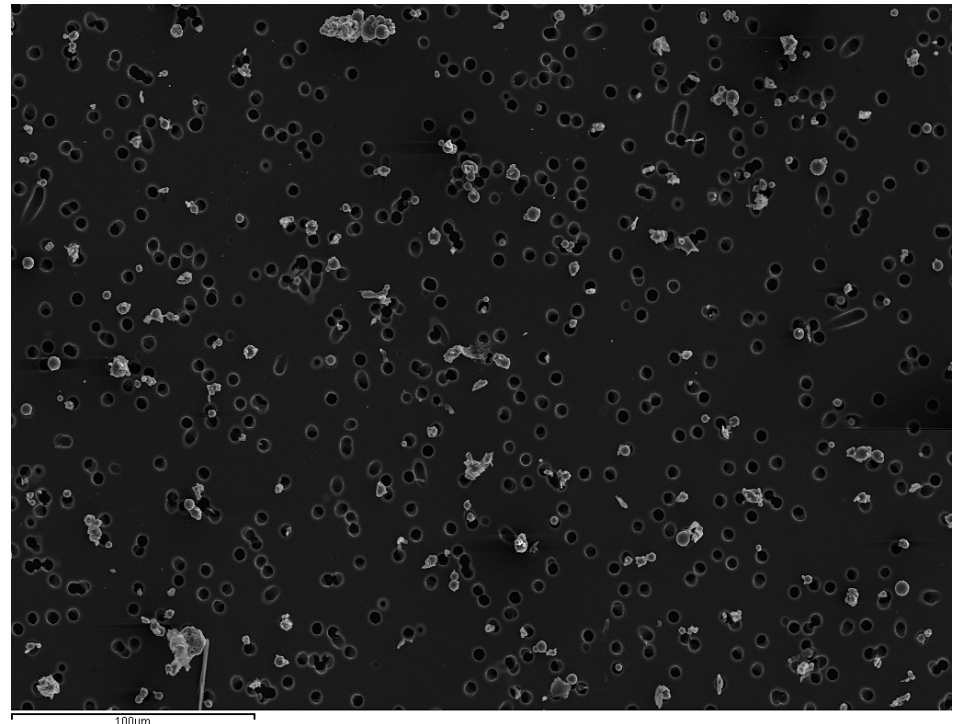

(b)

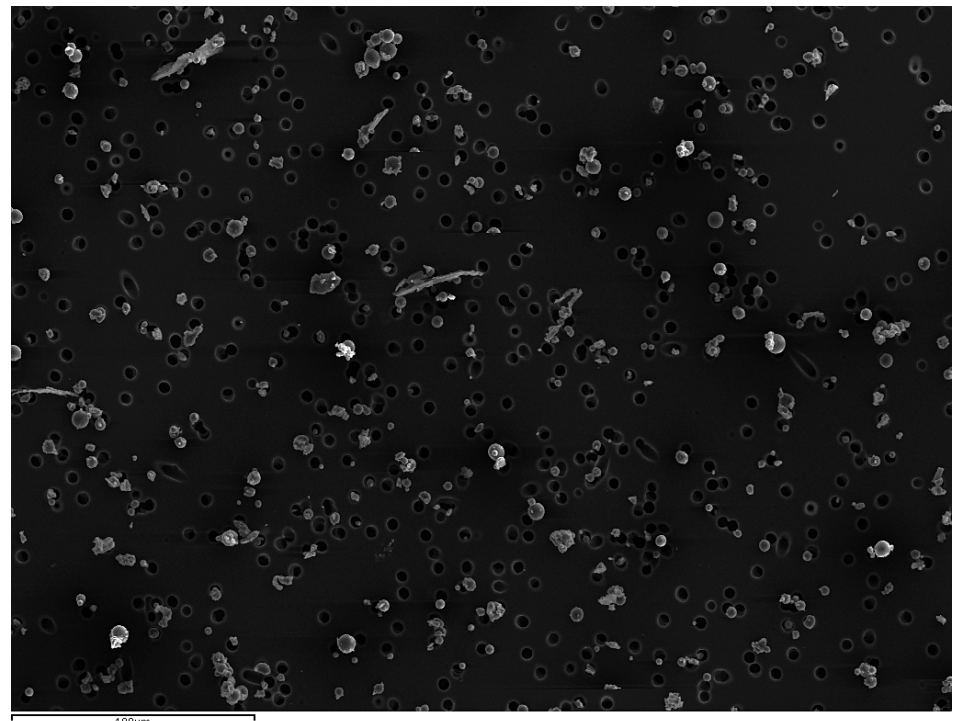

(c) 


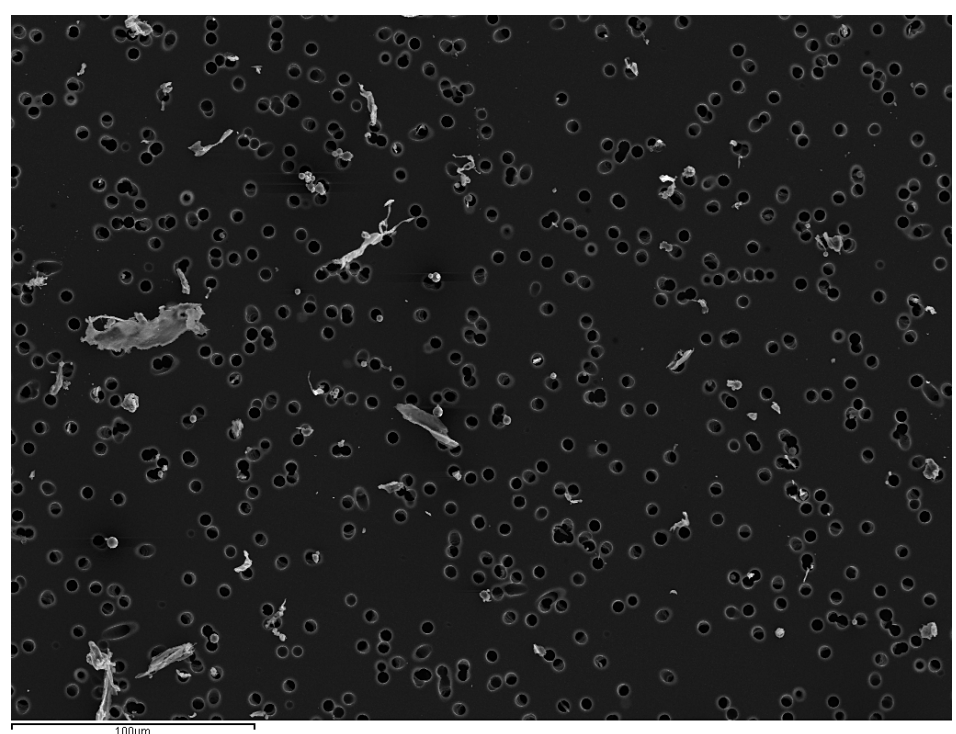

(d)

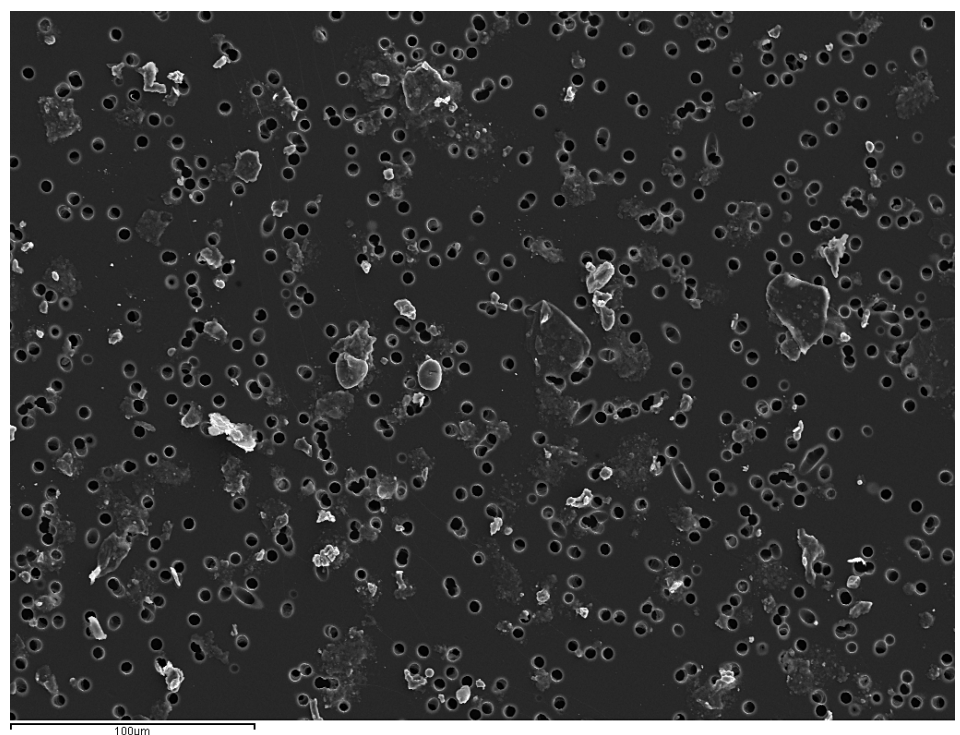

(e)

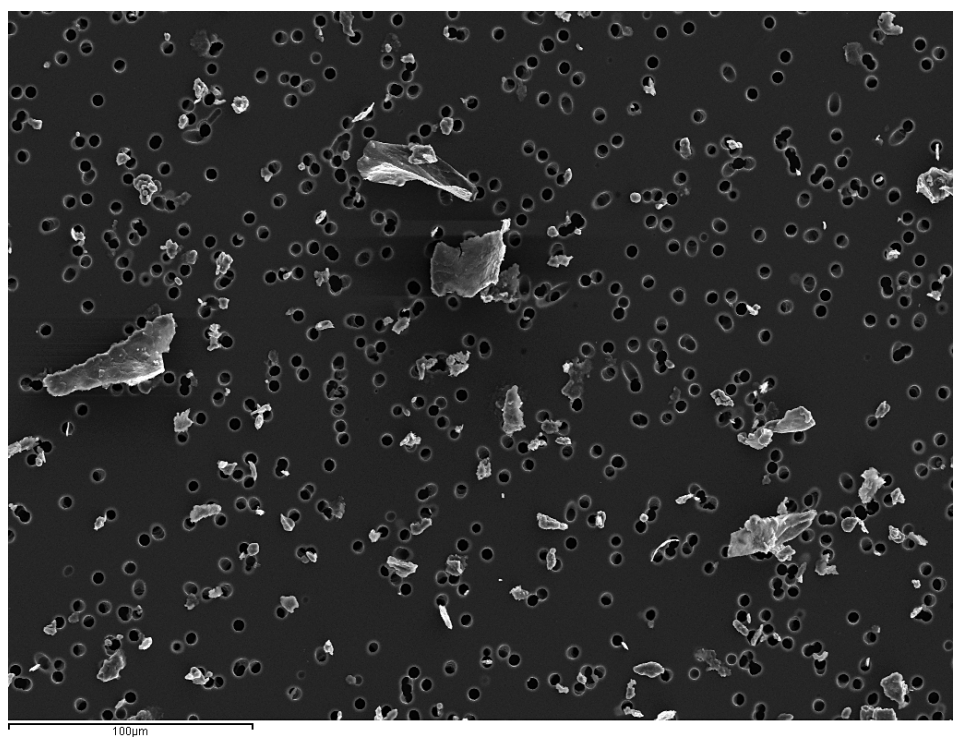




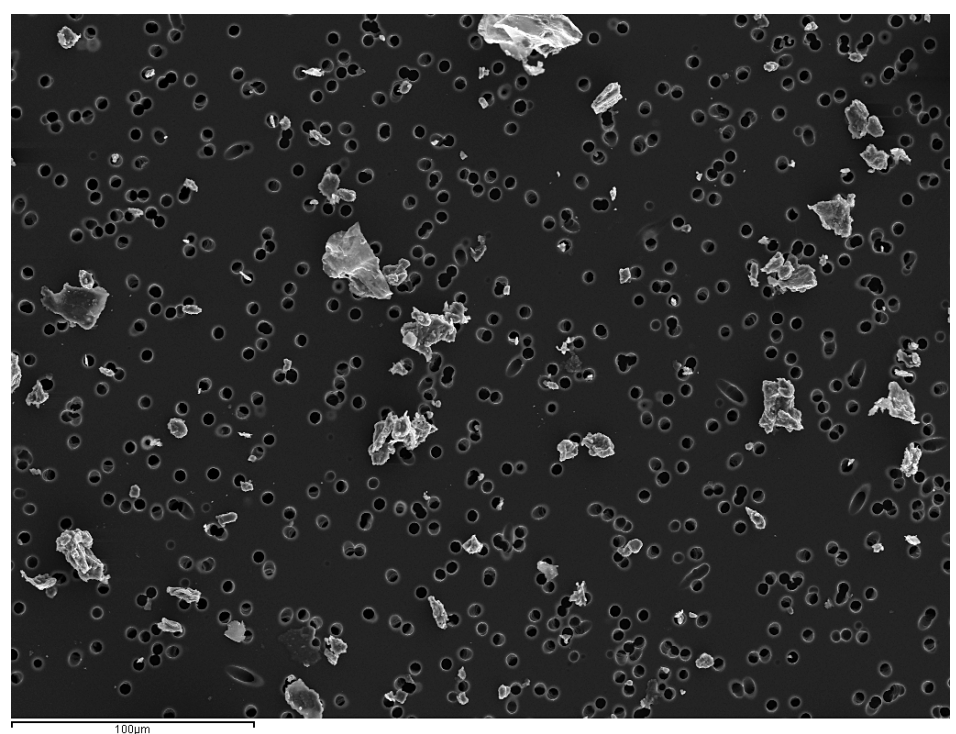

(g)

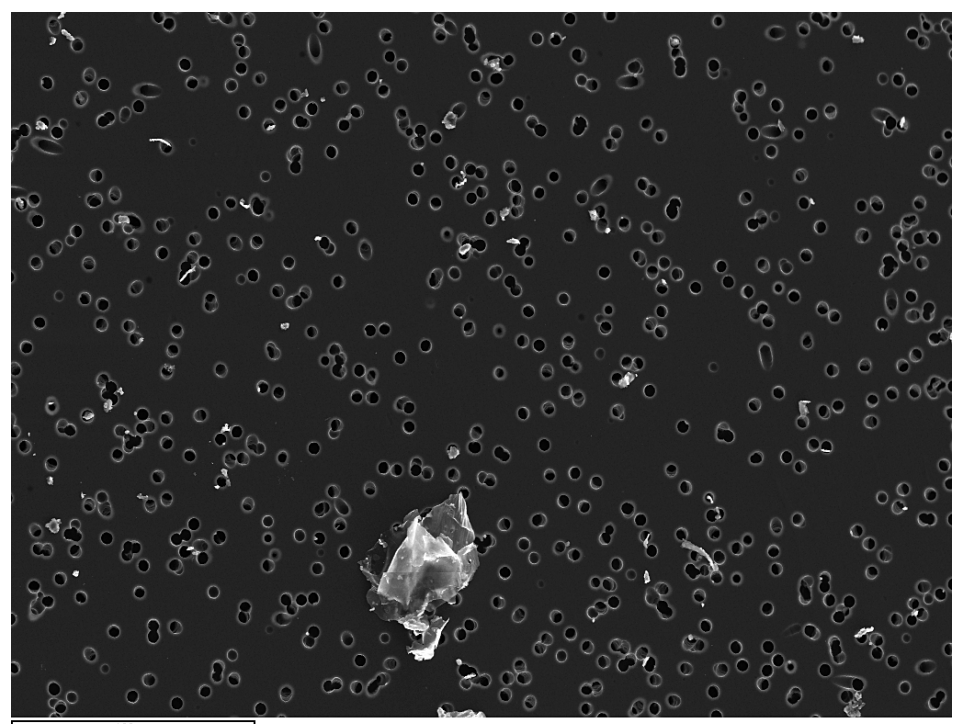

(h)

Figure 1. Examples of SEM images from on-farm airborne PM samples collected on polycarbonate filters $(5 \mu \mathrm{m}$ diameter filter pores shown as round dark holes). (a) Particles from broiler houses. Spherical particles from (b) laying hens with floor housing system and (c) laying hens with aviary system. (d) Particles from turkey houses. (e and f) Particles from piglet houses. (g) Mixture of particles from growing-finishing pig houses. (h) Large skin particles from dry and pregnant sow houses. Scale shown as white bar (scale bar $=100 \mu \mathrm{m})$.

Table 3. Average percentage number contribution of the different PM sources to airborne fine PM (PM $\mathbf{P M}_{2.5}$ from different animal housing systems and accuracy of the classification. Standard error (SE) represents variation in the contribution between both surveyed animal houses for the same animal category.

\begin{tabular}{|c|c|c|c|c|c|c|c|c|c|c|c|c|c|c|}
\hline \multirow[b]{2}{*}{ Source } & \multicolumn{2}{|c|}{ Broilers } & \multicolumn{2}{|c|}{$\begin{array}{l}\text { Laying Hens, } \\
\text { Floor } \\
\end{array}$} & \multicolumn{2}{|c|}{$\begin{array}{l}\text { Laying Hens, } \\
\text { Aviary }\end{array}$} & \multicolumn{2}{|c|}{ Turkeys } & \multicolumn{2}{|c|}{ Piglets } & \multicolumn{2}{|c|}{$\begin{array}{c}\text { Growing- } \\
\text { Finishing Pigs }\end{array}$} & \multicolumn{2}{|c|}{$\begin{array}{c}\text { Dry and } \\
\text { Pregnant Sows }\end{array}$} \\
\hline & Avg. & SE & Avg. & SE & Avg. & SE & Avg. & SE & Avg. & SE & Avg. & SE & Avg. & SE \\
\hline Feathers & 30.1 & 20.7 & 38.4 & 22.9 & 10.5 & 5.8 & 27.3 & 19.1 & -- & -- & -- & -- & -- & -- \\
\hline Feed & 8.1 & 8.1 & 3.0 & 1.8 & 2.4 & 2.4 & 1.7 & 1.7 & 15.9 & 5.1 & 3.7 & 1.5 & 14.5 & 2.2 \\
\hline Manure & 14.0 & 7.3 & 49.5 & 22.0 & 84.7 & 1.0 & 8.9 & 8.9 & 73.9 & 1.6 & 88.8 & 1.3 & 69.8 & 2.4 \\
\hline Outside & 28.8 & 9.1 & 9.2 & 0.8 & 2.4 & 2.4 & 44.3 & 37.1 & 7.0 & 5.3 & 5.4 & 0.1 & 4.1 & 4.1 \\
\hline Skin & -- & -- & -- & -- & -- & -- & -- & -- & 3.2 & 1.4 & 2.1 & 0.1 & 11.7 & 0.6 \\
\hline Wood shavings & 19.0 & 10.8 & -- & -- & -- & -- & 17.8 & 10.8 & -- & -- & -- & -- & -- & -- \\
\hline Accuracy $(\%)$ & \multicolumn{2}{|c|}{73 to 86} & \multicolumn{2}{|c|}{73 to 74} & \multicolumn{2}{|c|}{52 to 75} & \multicolumn{2}{|c|}{67 to 83} & \multicolumn{2}{|c|}{57 to 79} & \multicolumn{2}{|c|}{78 to 84} & \multicolumn{2}{|c|}{74 to 75} \\
\hline
\end{tabular}


Table 4. Average percentage number contribution of the different $P M$ sources to airborne coarse $P M\left(P M M_{10-2.5}\right)$ from different animal housing systems and accuracy of the classification. Standard error (SE) represents variation in the contribution between both surveyed animal houses for the same animal category.

\begin{tabular}{|c|c|c|c|c|c|c|c|c|c|c|c|c|c|c|}
\hline \multirow[b]{2}{*}{ Source } & \multicolumn{2}{|c|}{ Broilers } & \multicolumn{2}{|c|}{$\begin{array}{l}\text { Laying Hens, } \\
\text { Floor }\end{array}$} & \multicolumn{2}{|c|}{$\begin{array}{l}\text { Laying Hens, } \\
\text { Aviary }\end{array}$} & \multicolumn{2}{|c|}{ Turkeys } & \multicolumn{2}{|c|}{ Piglets } & \multicolumn{2}{|c|}{$\begin{array}{l}\text { Growing- } \\
\text { Finishing Pigs }\end{array}$} & \multicolumn{2}{|c|}{$\begin{array}{c}\text { Dry and } \\
\text { Pregnant Sows }\end{array}$} \\
\hline & Avg. & SE & Avg. & SE & Avg. & SE & Avg. & $\mathrm{SE}$ & Avg. & SE & Avg. & $\mathrm{SE}$ & Avg. & $\mathrm{SE}^{[\mathrm{a}]}$ \\
\hline Feathers & 35.1 & 13.1 & 12.8 & 1.9 & 8.9 & 2.7 & 32.4 & 17.6 & -- & -- & -- & -- & -- & -- \\
\hline Feed & 8.2 & 1.8 & 2.5 & 1.5 & 2.5 & 0.0 & 3.7 & 1.7 & 14.1 & 7.0 & 5.0 & 0.7 & 6.3 & -- \\
\hline Manure & 29.8 & 7.2 & 83.6 & 1.5 & 86.7 & 4.7 & 40.7 & 8.0 & 41.3 & 34.1 & 71.0 & 0.4 & 84.1 & -- \\
\hline Outside & 16.5 & 4.5 & 1.0 & 0.0 & 1.9 & 1.9 & 13.7 & 7.9 & 11.6 & 9.8 & 10.8 & 6.6 & 1.6 & -- \\
\hline Skin & -- & -- & -- & -- & -- & -- & -- & -- & 33.0 & 31.3 & 13.1 & 5.5 & 7.9 & -- \\
\hline Wood shavings & 10.3 & 0.3 & -- & -- & -- & -- & 9.5 & 0.1 & -- & -- & -- & -- & -- & -- \\
\hline Accuracy $(\%)$ & \multicolumn{2}{|c|}{76 to 85} & \multicolumn{2}{|c|}{78 to 88} & \multicolumn{2}{|c|}{75 to 84} & \multicolumn{2}{|c|}{62 to 76} & \multicolumn{2}{|c|}{74 to 79} & \multicolumn{2}{|c|}{78 to 81} & \multicolumn{2}{|c|}{63} \\
\hline
\end{tabular}

[a] No standard error because missing values for one farm.

Table 5. Average percentage number contribution of the different $P M$ sources to airborne fine $P M\left(P M M_{2.5}\right)$ from different animal housing systems and variance explained by the regression model $\left(R^{2}\right)$. Standard error (SE) represents variation in the contribution between both surveyed animal houses for the same animal category.

\begin{tabular}{|c|c|c|c|c|c|c|c|c|c|c|c|c|c|c|}
\hline \multirow[b]{2}{*}{ Source } & \multicolumn{2}{|c|}{ Broilers } & \multicolumn{2}{|c|}{$\begin{array}{l}\text { Laying Hens, } \\
\text { Floor }\end{array}$} & \multicolumn{2}{|c|}{$\begin{array}{c}\text { Laying Hens, } \\
\text { Aviary }\end{array}$} & \multicolumn{2}{|c|}{ Turkeys } & \multicolumn{2}{|c|}{ Piglets } & \multicolumn{2}{|c|}{$\begin{array}{c}\text { Growing- } \\
\text { Finishing Pigs }\end{array}$} & \multicolumn{2}{|c|}{$\begin{array}{c}\text { Dry and } \\
\text { Pregnant Sows }\end{array}$} \\
\hline & Avg. & $\mathrm{SE}$ & Avg. & $\mathrm{SE}$ & Avg. & $\mathrm{SE}$ & Avg. & $\mathrm{SE}$ & Avg. & SE & Avg. & $\mathrm{SE}$ & Avg. & $\mathrm{SE}$ \\
\hline Feathers & 28.4 & 21.5 & 4.4 & 1.1 & 16.0 & 8.7 & 43.2 & 15.3 & -- & -- & -- & -- & -- & -- \\
\hline Feed & 0.0 & 0.0 & 9.6 & 9.6 & 0.0 & 0.0 & 0.0 & 0.0 & 2.4 & 2.4 & 0.4 & 0.4 & 0.7 & 0.7 \\
\hline Manure & 67.7 & 18.2 & 74.2 & 1.8 & 84.0 & 8.7 & 22.9 & 12.8 & 91.2 & 4.0 & 98.3 & 1.7 & 78.9 & 4.1 \\
\hline Outside & 0.3 & 0.3 & 11.8 & 8.9 & 0.0 & 0.0 & 0.2 & 0.2 & 6.4 & 6.4 & 1.0 & 1.0 & 0.4 & 0.4 \\
\hline Skin & -- & -- & -- & -- & -- & -- & -- & -- & 0.0 & 0.0 & 0.4 & 0.4 & 20.0 & 4.4 \\
\hline Wood shavings & 3.5 & 3.5 & -- & -- & -- & -- & 33.7 & 2.7 & -- & -- & -- & -- & -- & -- \\
\hline $\mathrm{R}^{2}$ value & \multicolumn{2}{|c|}{0.79 to 0.82} & \multicolumn{2}{|c|}{0.49 to 0.87} & \multicolumn{2}{|c|}{0.94 to 0.96} & \multicolumn{2}{|c|}{0.88 to 0.97} & \multicolumn{2}{|c|}{0.43 to 0.74} & \multicolumn{2}{|c|}{0.78 to 0.96} & \multicolumn{2}{|c|}{0.71 to 0.78} \\
\hline
\end{tabular}

Table 6. Average percentage number contribution of the different PM sources to airborne coarse $\left.\mathbf{P M}_{(\mathbf{P M}} \mathrm{PM}_{10.5}\right)$ from different animal housing systems and variance explained by the regression model $\left(R^{2}\right)$. Standard error $(S E)$ represents variation in the contribution between both surveyed animal houses for the same animal category.

\begin{tabular}{|c|c|c|c|c|c|c|c|c|c|c|c|c|c|c|}
\hline \multirow[b]{2}{*}{ Source } & \multicolumn{2}{|c|}{ Broilers } & \multicolumn{2}{|c|}{$\begin{array}{l}\text { Laying Hens, } \\
\text { Floor }\end{array}$} & \multicolumn{2}{|c|}{$\begin{array}{c}\text { Laying Hens, } \\
\text { Aviary }\end{array}$} & \multicolumn{2}{|c|}{ Turkeys } & \multicolumn{2}{|c|}{ Piglets } & \multicolumn{2}{|c|}{$\begin{array}{c}\text { Growing- } \\
\text { Finishing Pigs }\end{array}$} & \multicolumn{2}{|c|}{$\begin{array}{c}\text { Dry and } \\
\text { Pregnant Sows }\end{array}$} \\
\hline & Avg. & SE & Avg. & SE & Avg. & SE & Avg. & SE & Avg. & SE & Avg. & SE & Avg. & $\mathrm{SE}^{[\mathrm{a}]}$ \\
\hline Feathers & 17.2 & 6.8 & 6.3 & 6.3 & 10.2 & 9.9 & 31.7 & 3.2 & -- & -- & -- & -- & -- & -- \\
\hline Feed & 0.0 & 0.0 & 0.0 & 0.0 & 0.0 & 0.0 & 0.0 & 0.0 & 6.0 & 6.0 & 4.2 & 4.2 & 0.0 & -- \\
\hline Manure & 82.8 & 6.8 & 93.7 & 6.3 & 87.7 & 7.8 & 35.8 & 1.5 & 94.0 & 6.0 & 84.5 & 1.8 & 85.4 & -- \\
\hline Outside & 0.0 & 0.0 & 0.0 & 0.0 & 2.2 & 2.2 & 0.0 & 0.0 & 0.0 & 0.0 & 0.0 & 0.0 & 0.0 & -- \\
\hline Skin & -- & -- & -- & -- & -- & -- & -- & -- & 0.0 & 0.0 & 11.3 & 2.4 & 14.6 & -- \\
\hline Wood shavings & 0.0 & 0.0 & -- & -- & -- & -- & 32.5 & 1.7 & -- & -- & -- & -- & -- & -- \\
\hline $\mathrm{R}^{2}$ value & \multicolumn{2}{|c|}{0.86 to 0.97} & \multicolumn{2}{|c|}{0.88 to 0.88} & \multicolumn{2}{|c|}{0.95 to 0.96} & \multicolumn{2}{|c|}{0.86 to 0.94} & \multicolumn{2}{|c|}{0.44 to 0.61} & \multicolumn{2}{|c|}{0.76 to 0.88} & \multicolumn{2}{|c|}{0.85} \\
\hline
\end{tabular}

[a] No standard error because missing values for one farm.

The standard errors of the estimated contributions presented in tables 3 and 4 showed that, in some cases, there were large differences in the contribution of the same source in different animal houses. This was especially the case for the outside source for turkeys in fine PM; and the contribution of manure and skin for piglets in coarse PM. Overall method accuracies calculated per farm using the cross-validation procedure and calculated as the number of correctly assigned particles to its reference source divided by the total number of classified particles varied from $52 \%$ to $88 \%$. Therefore, classification rules could successfully distinguish more than $50 \%$ of particles and correctly assign them to its reference source.

\section{Using Multiple Linear Regression}

Results using multiple linear regression are shown in table 5 (fine PM) and table 6 (coarse PM), together with the variance explained by the regression model. Results showed higher relative percentage contributions of manure to fine and coarse PM, and mostly lower contributions of feed and outside PM, compared with results when using classification rules based on decision trees. For piglets, there was no estimated contribution of skin to number of particles, whereas manure particles were dominant in fine and coarse fractions. Overall, results indicated that for poultry, most of the PM originated from feathers and manure. The relative percentage contribution of manure was again higher in coarse PM (ranging from 36\% to 94\%) compared with fine PM (ranging from 23\% to $84 \%$ ). The relative percentage contribution of manure was also higher in laying hen houses compared with broilers and turkeys; whereas the relative percentage contribution of feathers was higher for broilers and turkeys compared with laying hens. Wood shavings showed higher relative percentage contributions for turkeys 
than for broilers, varying from $33 \%$ to $34 \%$ in fine and coarse PM for turkeys. For pigs, very high percentage contributions from manure were found. The relative percentage contribution of manure was again higher in fine PM (ranging from $79 \%$ to $98 \%$ ) compared with coarse PM (ranging from $85 \%$ to $94 \%$ ). The relative percentage contribution of skin to coarse PM was lower (below 20\%) compared with classification rules based on decisions trees. The relative percentage contribution of feed was estimated to be low (at or below $10 \%$ ). It was generally higher for pigs compared with poultry, especially in coarse PM, where the contribution of feed was zero for all poultry categories. The relative percentage contribution of the outside source was very low. Standard errors of the estimated contributions between the surveyed animal houses were generally lower than using classification rules based on decision trees. The variation explained by the model varied from $43 \%$ to $97 \%$.

\section{Contribution of Sources to On-Farm Airborne PM EXPRESSED IN MASS}

Applying equation 2, average mass per source in each animal house was calculated. The relative percentage contribution results presented in tables 3 to 6 were weighed by the average mass of each PM source in each animal house to express percentage contribution of sources to on-farm airborne PM in mass.

\section{Using Classification Rules Based on Decision Trees}

Results using classification rules based on decision trees shown in table 7 (fine PM) and table 8 (coarse PM) show different relative source contributions from number contributions. Although for poultry most of the number of particles originated from feathers and manure, the contribution of feathers decreased for broilers but increased or did not vary for laying hens and turkeys when expressed in mass. In mass, the relative percentage contribution of manure was higher for laying hens compared with broilers and turkeys (same as for numbers), but the relative percentage contribution of feathers was higher for laying hens, especially compared with broilers. Although for pigs most particles originated from manure, the mass contribution of skin considerably increased compared with number contributions, in some cases ten-fold, ranging from $29 \%$ to $68 \%$ when expressed in mass, and thus decreasing the contribution of manure to below $65 \%$ in fine PM and below $41 \%$ in coarse PM. Wood shavings showed approximately a two-fold increase in mass compared with number contributions, whereas the relative percentage contribution of feed and outside did not vary or was generally lower compared with number contributions.

\section{Using Multiple Linear Regression}

Results using multiple linear regression are shown in table 9 (fine PM) and table 10 (coarse PM). These results are comparable to using classification rules based on decision trees, showing similar trends and differences when compared with number contributions, increasing the relative percentage contribution of feathers for laying hens, of manure for broilers and turkeys, and of skin for pigs.

\section{Comparison Between Methods}

Results between classification rules based on decision trees and multiple linear regression in number of particles showed relatively high linear correlations $\left(\mathrm{R}^{2}=0.75\right.$ for fine $\mathrm{PM}$ and $\mathrm{R}^{2}=0.61$ for coarse PM) (fig. 2). Correlations were higher for fine PM compared with coarse PM, probably influenced by the disagreement in the contribution of skin for piglets in coarse PM between methods.

Table 7. Average percentage mass contribution of the different PM sources to airborne fine $\left.\mathbf{P M}_{(\mathbf{P M}} \mathbf{P M}_{2.5}\right)$ from different animal housing systems using classification rules based on decision trees. Standard error (SE) represents variation in the contribution between both surveyed animal houses for the same animal category.

\begin{tabular}{|c|c|c|c|c|c|c|c|c|c|c|c|c|c|c|}
\hline \multirow[b]{2}{*}{ Source } & \multicolumn{2}{|c|}{ Broilers } & \multicolumn{2}{|c|}{$\begin{array}{l}\text { Laying Hens, } \\
\text { Floor }\end{array}$} & \multicolumn{2}{|c|}{$\begin{array}{c}\text { Laying Hens, } \\
\text { Aviary }\end{array}$} & \multicolumn{2}{|c|}{ Turkeys } & \multicolumn{2}{|c|}{ Piglets } & \multicolumn{2}{|c|}{$\begin{array}{l}\text { Growing- } \\
\text { Finishing Pigs }\end{array}$} & \multicolumn{2}{|c|}{$\begin{array}{c}\text { Dry and } \\
\text { Pregnant Sows }\end{array}$} \\
\hline & Avg. & SE & Avg. & $\mathrm{SE}$ & Avg. & SE & Avg. & SE & Avg. & SE & Avg. & SE & Avg. & SE \\
\hline Feathers & 17.3 & 14.9 & 67.9 & 0.5 & 21.5 & 0.5 & 30.3 & 14.6 & -- & -- & -- & -- & -- & -- \\
\hline Feed & 14.4 & 14.4 & 3.1 & 0.7 & 1.1 & 1.1 & 2.8 & 2.8 & 4.0 & 0.2 & 2.4 & 0.9 & 36.0 & 21.3 \\
\hline Manure & 12.9 & 6.4 & 25.5 & 2.8 & 76.5 & 1.4 & 5.9 & 5.9 & 62.1 & 18.2 & 65.0 & 0.4 & 13.9 & 1.3 \\
\hline Outside & 25.2 & 9.3 & 3.5 & 1.6 & 0.8 & 0.8 & 33.5 & 33.2 & 3.3 & 2.4 & 3.7 & 0.3 & 0.8 & 0.8 \\
\hline Skin & -- & -- & -- & -- & -- & -- & -- & -- & 30.6 & 15.5 & 28.9 & 0.8 & 49.4 & 19.2 \\
\hline Wood shavings & 30.3 & 16.3 & -- & -- & -- & -- & 27.5 & 15.5 & -- & -- & -- & -- & -- & -- \\
\hline
\end{tabular}

Table 8. Average percentage mass contribution of the different PM sources to airborne coarse $P M\left(P M M_{10-2.5}\right)$ from different animal housing systems using classification rules based on decision trees. Standard error (SE) represents variation in the contribution between both surveyed animal houses for the same animal category.

\begin{tabular}{|c|c|c|c|c|c|c|c|c|c|c|c|c|c|c|}
\hline \multirow[b]{2}{*}{ Source } & \multicolumn{2}{|c|}{ Broilers } & \multicolumn{2}{|c|}{$\begin{array}{l}\text { Laying Hens, } \\
\text { Floor }\end{array}$} & \multicolumn{2}{|c|}{$\begin{array}{c}\text { Laying Hens, } \\
\text { Aviary }\end{array}$} & \multicolumn{2}{|c|}{ Turkeys } & \multicolumn{2}{|c|}{ Piglets } & \multicolumn{2}{|c|}{$\begin{array}{c}\text { Growing- } \\
\text { Finishing Pigs }\end{array}$} & \multicolumn{2}{|c|}{$\begin{array}{c}\text { Dry and } \\
\text { Pregnant Sows }\end{array}$} \\
\hline & Avg. & $\mathrm{SE}$ & Avg. & SE & Avg. & SE & Avg. & SE & Avg. & $\mathrm{SE}$ & Avg. & SE & Avg. & $\mathrm{SE}^{[\mathrm{a}]}$ \\
\hline Feathers & 9.2 & 1.8 & 37.8 & 3.7 & 31.5 & 9.8 & 48.6 & 28.3 & -- & -- & -- & -- & -- & -- \\
\hline Feed & 2.4 & 1.2 & 3.7 & 2.3 & 1.3 & 0.9 & 1.7 & 1.6 & 5.6 & 5.0 & 1.1 & 0.2 & 2.5 & -- \\
\hline Manure & 47.2 & 30.1 & 57.4 & 5.0 & 63.8 & 12.3 & 31.3 & 20.1 & 31.2 & 30.8 & 23.4 & 6.8 & 40.8 & -- \\
\hline Outside & 3.2 & 1.5 & 1.1 & 0.9 & 3.4 & 3.4 & 4.4 & 3.7 & 4.2 & 1.9 & 7.6 & 4.0 & 1.7 & -- \\
\hline Skin & -- & -- & -- & -- & -- & -- & -- & -- & 59.0 & 33.9 & 67.9 & 11.0 & 55.0 & -- \\
\hline Wood shavings & 38.1 & 29.2 & -- & -- & -- & -- & 13.9 & 3.0 & -- & -- & -- & -- & -- & -- \\
\hline
\end{tabular}

[a] No standard error because missing values for one farm. 
Table 9. Average percentage mass contribution of the different PM sources to airborne fine $\mathbf{P M}\left(\mathbf{P M}_{2.5}\right)$

from different animal housing systems using multiple linear regression. Standard error (SE) represents variation in the contribution between both surveyed animal houses for the same animal category.

\begin{tabular}{|c|c|c|c|c|c|c|c|c|c|c|c|c|c|c|}
\hline \multirow[b]{2}{*}{ Source } & \multicolumn{2}{|c|}{ Broilers } & \multicolumn{2}{|c|}{$\begin{array}{l}\text { Laying Hens, } \\
\text { Floor }\end{array}$} & \multicolumn{2}{|c|}{$\begin{array}{c}\text { Laying Hens, } \\
\text { Aviary }\end{array}$} & \multicolumn{2}{|c|}{ Turkeys } & \multicolumn{2}{|c|}{ Piglets } & \multicolumn{2}{|c|}{$\begin{array}{l}\text { Growing- } \\
\text { Finishing Pigs }\end{array}$} & \multicolumn{2}{|c|}{$\begin{array}{c}\text { Dry and } \\
\text { Pregnant Sows }\end{array}$} \\
\hline & Avg. & SE & Avg. & SE & Avg. & SE & Avg. & SE & Avg. & SE & Avg. & SE & Avg. & $\mathrm{SE}$ \\
\hline Feathers & 21.3 & 19.5 & 17.0 & 12.0 & 36.3 & 26.0 & 39.1 & 16.8 & -- & -- & -- & -- & -- & -- \\
\hline Feed & 0.0 & 0.0 & 23.2 & 23.2 & 0.0 & 0.0 & 0.0 & 0.0 & 0.4 & 0.4 & 0.7 & 0.7 & 3.8 & 3.8 \\
\hline Manure & 72.1 & 14.3 & 54.2 & 6.8 & 63.7 & 26.0 & 34.8 & 17.1 & 94.5 & 4.6 & 92.8 & 7.2 & 17.2 & 6.2 \\
\hline Outside & 0.7 & 0.7 & 5.5 & 4.4 & 0.0 & 0.0 & 0.1 & 0.1 & 5.0 & 5.0 & 0.9 & 0.9 & 0.1 & 0.1 \\
\hline Skin & -- & -- & -- & -- & -- & -- & -- & -- & 0.0 & 0.0 & 5.7 & 5.7 & 79.0 & 10.0 \\
\hline Wood shavings & 5.8 & 5.8 & -- & -- & -- & -- & 26.1 & 0.3 & -- & -- & -- & -- & -- & -- \\
\hline
\end{tabular}

Table 10. Average percentage mass contribution of the different PM sources to airborne coarse $P M\left(P M_{10-2.5}\right)$ from different animal housing systems using multiple linear regression. Standard error (SE) represents variation in the contribution between both surveyed animal houses for the same animal category.

\begin{tabular}{|c|c|c|c|c|c|c|c|c|c|c|c|c|c|c|}
\hline \multirow[b]{2}{*}{ Source } & \multicolumn{2}{|c|}{ Broilers } & \multicolumn{2}{|c|}{$\begin{array}{l}\text { Laying Hens, } \\
\text { Floor }\end{array}$} & \multicolumn{2}{|c|}{$\begin{array}{l}\text { Laying Hens, } \\
\text { Aviary }\end{array}$} & \multicolumn{2}{|c|}{ Turkeys } & \multicolumn{2}{|c|}{ Piglets } & \multicolumn{2}{|c|}{$\begin{array}{l}\text { Growing- } \\
\text { Finishing Pigs }\end{array}$} & \multicolumn{2}{|c|}{$\begin{array}{c}\text { Dry and } \\
\text { Pregnant Sows }\end{array}$} \\
\hline & Avg. & SE & Avg. & SE & Avg. & SE & Avg. & SE & Avg. & $\mathrm{SE}$ & Avg. & SE & Avg. & $\mathrm{SE}^{[\mathrm{a}]}$ \\
\hline Feathers & 4.4 & 1.7 & 14.5 & 14.5 & 30.0 & 29.0 & 25.1 & 2.8 & -- & -- & -- & -- & -- & -- \\
\hline Feed & 0.0 & 0.0 & 0.0 & 0.0 & 0.0 & 0.0 & 0.0 & 0.0 & 7.9 & 7.9 & 1.1 & 1.1 & 0.0 & -- \\
\hline Manure & 95.6 & 1.7 & 85.5 & 14.5 & 69.6 & 28.6 & 51.9 & 1.8 & 92.1 & 7.9 & 29.8 & 3.3 & 29.1 & -- \\
\hline Outside & 0.0 & 0.0 & 0.0 & 0.0 & 0.4 & 0.4 & 0.0 & 0.0 & 0.0 & 0.0 & 0.0 & 0.0 & 0.0 & -- \\
\hline Skin & -- & -- & -- & -- & -- & -- & -- & -- & 0.0 & 0.0 & 69.1 & 4.4 & 70.9 & -- \\
\hline Wood shavings & 0.0 & 0.0 & -- & -- & -- & -- & 22.9 & 1.0 & -- & -- & -- & -- & -- & -- \\
\hline
\end{tabular}

[a] No standard error because missing values for one farm.
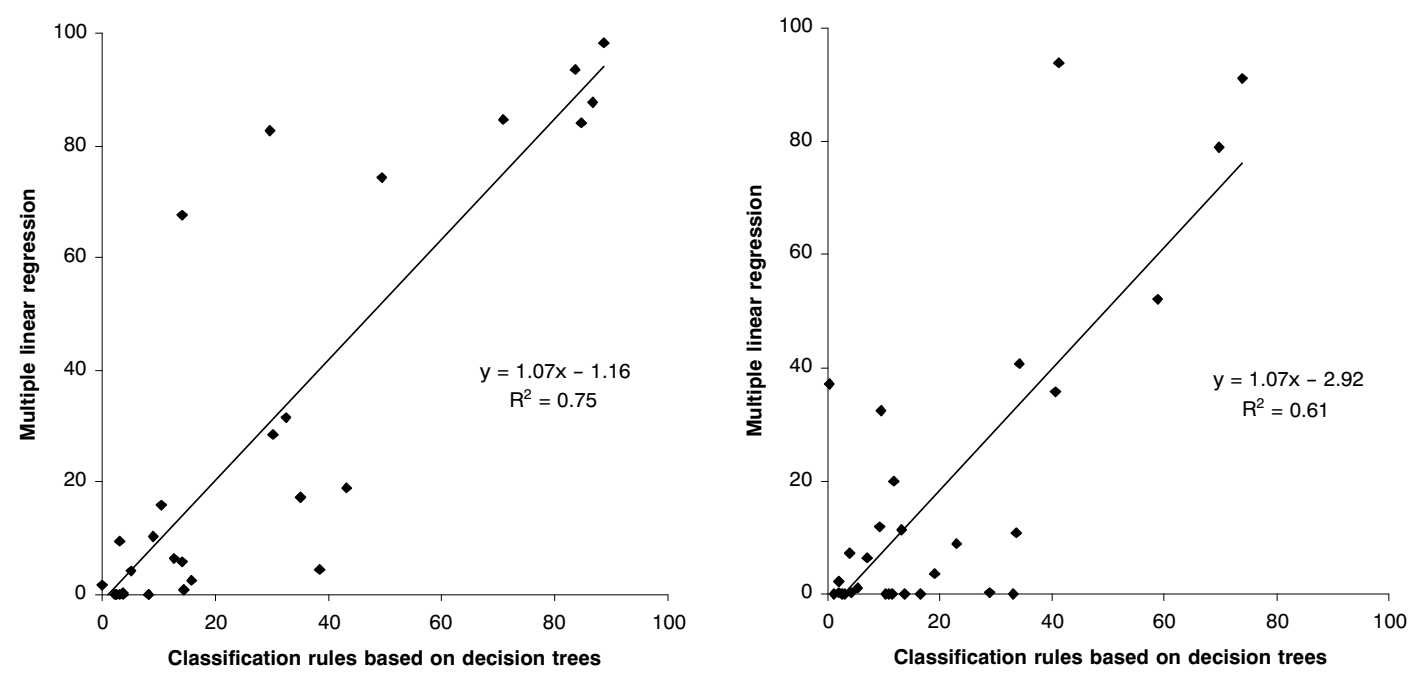

Figure 2. Linear relationship between classification rules based on decision trees and multiple linear regression source apportionment results in number of particles, for fine PM (left) and coarse PM (right).

\section{DiscuSSION}

Our results have been presented and analyzed as relative percentage contributions. If we expressed the relative percentage contribution in absolute terms considering the total PM concentrations, these source contributions could vary. Under the environmental conditions experienced during sampling in this study (table 2), $\mathrm{PM}_{10}$ concentrations in poultry houses were consistently higher compared with pig houses. Therefore, it can be expected that expressed in absolute source contributions, minor sources for poultry become more important compared with pigs. Although the relative percentage contributions are also influenced by the number and type of sources, they still provide valuable quantitative estimations of the major sources per animal category. We infer differences in relative percentage source contributions among the animal categories to be related to the particles' morphological and thus aerodynamic characteristics, which can affect their airborne properties, together with the intrinsic differences and presence of sources per animal category and specific housing systems.

Based on particle numbers, feathers (relative percentage contribution ranging from $4 \%$ to $43 \%$ in fine and from $6 \%$ to $35 \%$ in coarse PM) and manure (ranging from $9 \%$ to $85 \%$ in fine and from $30 \%$ to $94 \%$ in coarse PM) were the most abundant sources for poultry. Manure (ranging from $70 \%$ to $98 \%$ in fine and from $41 \%$ to $94 \%$ in coarse PM) was the most 
abundant source for pigs. Differences in source contributions among the animal species were mainly related to the housing system and the presence of bedding, especially for broilers and turkeys. Morphology of the particles from the different sources could also explain such differences, for instance, the relatively higher contribution of feathers for broilers and turkeys compared with laying hens. Broiler and turkey feathers are generally lighter and looser, fluffier in appearance (corresponding to plumules or down feathers), than adult feathers as found on laying hens (Cambra-López et al., 2011). Consequently, broiler and turkey feathers are probably more prone to become airborne.

The relative percentage contribution of feed (which was below $16 \%$ in all cases) varied among animal species, being higher in pig houses compared with poultry houses. Perhaps the type of feed and the feed processing could explain such differences, as poultry feed is generally less ground than pig feeds. The relative percentage contribution of outside particles was higher in the pig houses compared with the poultry houses, which were all tunnel ventilated except for turkeys (which also showed high outside PM contribution) compared with ceiling ventilation in pig houses.

Similar sources have been identified and similar number contributions have been reported in other studies. Donham et al. (1986) showed higher contributions of manure particles in the fine fraction of PM compared with larger particles in pig houses, as in this study. For poultry, we found higher numbers of manure particles in coarse PM than for pigs. The existence of two distinctive morphological types of manure particles between poultry and pigs could be the cause of this difference. Poultry excrete encapsulated uric acid crystals, which are identified as round, smooth, spherical particles that can easily agglomerate, increasing in size (Casotti and Braun, 2004). For pigs, however, this type of excretion does not exist, and the manure particles are generally smaller, fragmented, rough, and angular particles, which are mostly found as individual particles falling into the fine range (Cambra-López et al., 2011).

Feed, manure, pig dander, mold, pollen and grains, insect parts, and mineral ash have been identified in PM samples from pig houses (Donham et al., 1986). The contribution of feed to PM in pig houses has been generally reported in higher ranges than those presented in this study. For finishing pigs, Heber et al. (1988) reported that most of PM originated from feed particles (about 65\%) and to a lesser extent from manure and skin. Aarnink et al. (1999) found a high contribution of feed for weaning pigs but also identified skin as a major source. For poultry, Aarnink et al. (1999) obtained comparable results to those reported in this study and identified down feathers and urine components as most abundant for broilers. Feddes et al. (1992) found fecal material, mainly uric acid crystals, as the main constituent in PM from turkey houses.

Fecal particles can morphologically resemble feed particles. Furthermore, undigested feed components could be found in manure. The higher proportion of feed particles found in other studies (mainly starch in pig houses) (Aarnink et al., 1999; Donham et al., 1986; Heber et al., 1988) could be attributable to the use of only light microscopy to distinguish between particles. Light microscopy uses lower magnifications compared with scanning electron microscopy, and thus it is more difficult to identify particle types and discriminate between similarly shaped particles with light microscopy than with SEM. Furthermore, to overcome the limitations of light microscopy, authors have used stains to distinguish starch (in feed) from manure. The use of stains may lead to misleading observations due to the presence of undigested feed components in particles from manure, and a higher content of starch found in pig feces compared with poultry (Feddes et al., 1992). This fact could also explain the higher proportion of feed particles in airborne PM presented in other studies. Moreover, total dust was used in previous studies, as opposed to fine and coarse segregated PM measurements as in our study. As reported by Feddes et al. (1992), the contribution of feed in particles bigger than $10 \mu \mathrm{m}$ can be 30 times higher in numbers compared with the 0 to 5 $\mu \mathrm{m}$ size range.

The large differences in source contributions for a given housing system between farms in our study, expressed as high standard errors, could be the result of the methodology used because source apportionment models usually show high variations. Moreover, this could have been caused by the different housing conditions during samplings, together with the short sampling times used. Differences in PM concentrations between farms with the same housing systems during sampling, as for turkeys (table 2), could also play a role in these differences. The PM concentrations and emissions in a given animal house can vary depending of the time of the day, e.g., PM increases with feeding time and lighting periods (Calvet et al., 2009; Hinz and Linke, 1998), and along a growing cycle, e.g., with animal age, age of the bedding, or cleaning of the rooms (Hinz and Linke, 1998; Redwine et al., 2002). Therefore, source contributions could vary depending on the farm activity within a day and also between days; thus, part of the between-farm variation could be due to on-farm variation. More frequent measurements in the same animal house over time could provide data to understand how PM source contributions can vary within a day and through a growing cycle. In our study, however, all sampling was conducted during the morning. During sampling, no specific farm activities, such as manure cleaning, were performed. Furthermore, all farms used automatically distributed feeding systems, meaning that the animals were fed ad libitum and there was no particular feeding moment because they had free access to feed. Therefore, within their limitations, our results can be applicable and representative of other farm situations.

Great variability between number and mass contributions results from the inherent variability of the morphological characteristics of PM (Cambra-López et al., 2011). Based on particle mass, feathers (relative percentage contribution ranging from $17 \%$ to $68 \%$ in fine and from $4 \%$ to $49 \%$ in coarse PM) and manure (ranging from $6 \%$ to $77 \%$ in fine and from $31 \%$ to $96 \%$ in coarse PM) were still the most abundant sources for poultry, whereas skin (relative percentage contribution ranging from $0 \%$ to $79 \%$ in fine and from $0 \%$ to $71 \%$ in coarse PM) and manure (relative percentage contribution ranging from $14 \%$ to $95 \%$ in fine and from $23 \%$ to $92 \%$ in coarse PM) were the most abundant for pigs. When estimating mass contributions, it can be expected that large particles with large projected area diameters, although less numerous, gain relative importance. This is the case for wood shavings, and especially for skin particles. Differences among sources from different animal species also result in different mass contributions of the sources. The different morphological characteristics of (down) feathers from 
broilers compared with feathers from laying hens could explain why feathers increase in relative contribution for laying hens when expressed in mass compared with numbers. The opposite occurs for broilers. Other studies have reported similar source mass contributions. For growing-fattening pigs, Aarnink et al. (2004) reported high mass contributions of skin, comparable to those reported in this study. Hair from pigs, which shows large projected area diameters (CambraLópez et al., 2011), could probably also gain relative importance when expressed in mass contributions.

Overall, both methods used in our study to quantify PM source contributions from animal houses presented comparable results. Although leave-one-out cross-validation could overestimate the predictive ability of the model, our results showed that it was a robust procedure within the context of this study. Therefore, both methods presented sufficient levels of accuracy for source apportionment of PM in animal houses, where the aim is to provide knowledge of the major sources that can be further used to develop new PM reduction techniques or optimize existing techniques. In this sense, the accuracies presented in this study can reasonably fulfill this aim. Therefore, using two independent methods, the contribution results were consistent between them $\left(\mathrm{R}^{2}=\right.$ 0.75 for fine $\mathrm{PM}$ and $\mathrm{R}^{2}=0.61$ for coarse $\left.\mathrm{PM}\right)$. Differences between both methods, however, can be explained by method characteristics, by the use of different particle characteristics (morphological and/or chemical), and consequently by the discrepancies between single-particle chemical and average (bulk) source compositions.

In our results, differences in the obtained source contributions between classification rules based on decision trees and multiple linear regression were mainly caused by a higher contribution of manure when using multiple linear regression. This can be because manure is one of the most well-defined and homogeneous sources in terms of element composition compared with other sources (Cambra-López et al., 2011). Therefore, the contribution of sources whose contributions were low using multiple linear regression (regression coefficients were very close to zero) could have been distributed among the manure source. Multiple linear regression apportioned PM to sources based on bulk particle chemical characteristics, and it searched for the combination that could predict better the changes in the dependent variable in relation to changes in the independent variables using the least-squares method. In fact, Almeida et al. (2006) reported that with this method, the proportion of "unknown" fraction would be distributed among the identified sources with properties in common. Furthermore, when there are discrepancies between single-particle chemical source characteristics and average (bulk) source compositions, or when sources are not well-defined and are not chemically homogeneous, single-particle classification might apportion more accurately to the sources that show a more heterogeneous element composition than using average source composition. This could be the case of feed and outside sources, which have been described as heterogeneous sources (Cambra-López et al., 2011) and which show, in this study, lower contributions when using multiple linear regression compared with classification rules based on decision trees.

The differences found for piglets between methods could possibly be explained by the abundance of deposited round, gray, smoothed particles in piglet houses in coarse PM (fig. 1e). The morphology of these particles probably corresponds to highly hygroscopic particles that were sampled under high humidity levels. It has been reported in the literature that particles can show an increase in size as they take up water and thus present this shape (Hiranuma et al., 2008). These particles, which showed large sizes, could have been confused with skin particles when using classification rules but not when using only chemical characteristics with multiple linear regression, where skin did not show such high contributions in piglets.

\section{Conclusions}

Results presented in this study improve the understanding of sources of PM in different animal housing systems, not only in numbers but also in mass contributions, which may be valuable when choosing optimal PM reduction techniques. From our results, we can conclude that:

- Using two independent methods, source apportionment results were consistent between classification rules based on decision trees and multiple linear regression $\left(\mathrm{R}^{2}=0.75\right.$ for fine $\mathrm{PM}$ and $\mathrm{R}^{2}=0.61$ for coarse $\mathrm{PM}$ ), and with detailed and specific chemical and morphological source profiles, both methods presented sufficient levels of accuracy for the aim of this study.

- Based on particle numbers, in poultry houses, most onfarm airborne PM originated from feathers (relative percentage contribution ranging from $4 \%$ to $43 \%$ in fine and from $6 \%$ to $35 \%$ in coarse PM) and manure (ranging from $9 \%$ to $85 \%$ in fine and from $30 \%$ to $94 \%$ in coarse PM).

- Based on particle numbers, in pig houses, most on-farm airborne PM originated from manure (relative percentage contribution ranging from $70 \%$ to $98 \%$ in fine and from $41 \%$ to $94 \%$ in coarse PM).

- Feed had a negligible contribution to on-farm airborne PM compared with the rest of the sources.

- Based on particle mass, in poultry houses, most onfarm airborne PM originated from feathers (relative percentage contribution ranging from $17 \%$ to $68 \%$ in fine and from $4 \%$ to $49 \%$ in coarse PM) and manure (ranging from $6 \%$ to $77 \%$ in fine and from $31 \%$ to $96 \%$ in coarse PM); but in pig houses most on-farm airborne $\mathrm{PM}$ originated from skin (ranging from $0 \%$ to $79 \%$ in fine and from $0 \%$ to $71 \%$ in coarse PM) and manure (ranging from $14 \%$ to $95 \%$ in fine and from $23 \%$ to $92 \%$ in coarse $\mathrm{PM}$ ).

\section{ACKNOWLEDGEMENTS}

We acknowledge the support of the Dutch Ministry of Agriculture, Nature, and Food Quality, which financed this study. We thank the Servicio de Microscopía Electrónica (Universidad Politécnica de Valencia) for expert technical assistance during SEM analysis. We would also wish to thank Prof. Dr. W. Koch (Fraunhofer Institute of Toxicology and Experimental Medicine, Hannover, Germany) for his kindness in lending us a RespiCon unit to perform real-time duplicate measurements. 


\section{REFERENCES}

Aarnink, A. J. A., P. F. M. M. Roelofs, H. H. Ellen, and H. Gunnink. 1999. Dust sources in animal houses. In Proc. Intl. Symp. Dust Control Animal Prod. Facilities, 34-40. Aarhus, Denmark: Danish Institute of Agricultural Sciences.

Aarnink, A. J. A., N. Stockhofe-Zurwieden, and M. J. M. Wagemans. 2004. Dust in different housing systems for growing-finishing pigs. In Proc. Intl. Conf. Agric. Eng. AgEng 2004. Leuven, Belgium.

Almeida, S. M., C. A. Pio, M. C. Freitas, M. A. Reis, and M. A. Trancoso. 2006. Approaching $\mathrm{PM}_{2.5}$ and $\mathrm{PM}_{2.5-10}$ source apportionment by mass balance analysis, principal component analysis and particle size distribution. Sci. Total Environ. 368(2-3): 663-674.

Blaschke, T. 2010. Object based image analysis for remote sensing. ISPRS J. Photogrammetry and Remote Sensing 65(1): 2-16.

Cai, L., J. A. Koziel, Y.-C. Lo, and S. J. Hoff. 2006. Characterization of volatile organic compounds and odorants associated with swine barn particulate matter using solid-phase microextraction and gas chromatography-mass spectrometryolfactometry. J. Chromatography A 1102(1-2): 60-72.

Calvet, S., H. Van den Weghe, R. Kosch, and F. Estellés. 2009. The influence of the lighting program on broiler activity and dust production. Poultry Sci. 88(12): 2504-2511.

Cambra-López, M., A. G. Torres, A. J. A. Aarnink, and N. W. M. Ogink. 2011. Source analysis of fine and coarse particulate matter from livestock houses. Atmos. Environ. 45(3): 694-707.

Casotti, G., and E. Braun. 2004. Protein location and elemental composition of urine spheres in different avian species. J. Exp. Zoology A 301(7): 579-587.

CEN. 1993. CEN-EN 481: Workplace atmospheres-Size fraction definitions for measurement of airborne particles. Brussels, Belgium: European Committee for Standardization.

Conner, T. L., G. A. Norris, M. S. Landis, and R. W. Williams. 2001. Individual particle analysis of indoor, outdoor, and community samples from the 1998 Baltimore particulate matter study. Atmos. Environ. 35(23): 3935-3946.

Donham, K. J., W. Popendorf, U. Palmgren, and L. Larsson. 1986. Characterization of dusts collected from swine confinement buildings. American J. Ind. Med. 10(3): 294-297.

Feddes, J. J. R., H. Cook, and M. J. Zuidhof. 1992. Characterization of airborne dust particles in turkey housing. Canadian Agric. Eng. 34(3): 273-280.

Freund, Y. 1995. Boosting a weak learning algorithm by majority. Info. Computation 121(2): 256-285.

Genstat Committee. 2008. Genstat 11th Edition. Version/ 11.1.0.1789. Hemel Hempstead, U.K.: VSN International, Ltd.

Gill, T. E., T. M. Zobeck, and J. E. Stout. 2006. Technologies for laboratory generation of dust from geological materials. $J$. Hazardous Materials 132(1): 1-13

Heber, A. J., M. Stroik, J. M. Faubion, and L. H. Willard. 1988. Size distribution and identification of aerial dust particles in swine finishing buildings. Trans. ASAE 31(3): 882-887.

Hinz, T., and S. Linke. 1998. A comprehensive experimental study of aerial pollutants in and emissions from livestock buildings: Part 2. Results. J. Agric. Eng. Res. 70(1): 119-129.

Hiranuma, N., S. D. Brooks, B. W. Auvermann, and R. Littleton. 2008. Using environmental scanning electron microscopy to determine the hygroscopic properties of agricultural aerosols. Atmos. Environ. 42(9): 1983-1994.
Honey, L. F., and J. B. McQuitty. 1979. Some physical factors affecting dust concentrations in a pig facility. Canadian Agric. Eng. 21(1): 9-14.

Hopke, P. K. 1991. Receptor Modeling for Air Quality Management. Amsterdam, The Netherlands: Elsevier.

Hopke, P. K. 2008. Quantitative results from single-particle characterization data. J. Chemometrics 22(9): 528-532.

Hopke, P. K., and X. H. Song. 1997. Classification of single particles by neural networks based on the computer-controlled scanning electron microscopy data. Analytica Chimica Acta 348(1-3): 375-388.

Jensen, J. R. 2005. Introductory Digital Image Processing. 3rd ed. Upper Saddle River, N.J.: Pearson Education.

Kim, D., and P. K. Hopke. 1988. Classification of individual particles based on computer-controlled scanning electron microscopy data. Aerosol Sci. Tech. 9(2): 133-151.

Lee, S. A., A. Adhikari, S. A. Grinshpun, R. McKay, R. Shukla, and T. Reponen. 2006. Personal exposure to airborne dust and microorganisms in agricultural environments. J. Occup. Environ. Hygiene 3(3): 118-130.

Li, S. N., D. A. Lundgren, and D. Rovell-Rixx. 2000. Evaluation of six inhalable aerosol samplers. AIHAJ 61(4): 506-516.

McCrone, W. C. 1992. The Particle Atlas Electronic Edition $\left(P A E^{2}\right)$. CD-ROM. Chicago, Ill.: McCrone Research Institute.

Ott, D. K., W. Cyrs, and T. M. Peters. 2008. Passive measurement of coarse particulate matter, $\mathrm{PM}_{10-2.5}$. J. Aerosol Sci. 39(2): 156-167.

Qi, R., H. B. Manbeck, and R. G. Maghirang. 1992. Dust net generation rate in a poultry layer house. Trans. ASAE 35(5): 1639-1645.

Quinlan, J. R. 1993. C4.5: Programs for Machine Learning. San Francisco, Cal.: Morgan Kaufmann.

Radon, K., C. Weber, M. Iversen, B. Danuser, S. Pedersen, and D. Nowak. 2001. Exposure assessment and lung function in pig and poultry farmers. Occup. Environ. Med. 58(6): 405-410.

Redwine, J. S., R. E. Lacey, S. Mukhtar, and J. B. Carey. 2002. Concentration and emissions of ammonia and particulate matter in tunnel-ventilated broiler houses under summer conditions in Texas. Trans. ASAE 45(4): 1101-1109.

Ruiz, L. A., J. A. Recio, A. Fernández-Sarría, and T. Hermosilla. 2011. A feature extraction software tool for agricultural object-based image analysis. Computers and Electronics in Agric. (in press) doi: 10.1016/j.compag.2011.02.007.

Watson, J. G., T. Zhu, J. C. Chow, J. Engelbrecht, E. M. Fujita, and W. E. Wilson. 2002. Receptor modeling application framework for particle source apportionment. Chemosphere 49(9): 1093-1136.

Wienke, D., Y. Xie, and P. K. Hopke. 1995. Classification of airborne particles by analytical scanning electron microscopy imaging and a modified Kohonen neural network (3MAP). Analytica Chimica Acta 310(1): 1-14.

Willis, R. D., F. T. Blanchard, and T. L. Conner. 2002. Guidelines for the application of SEM/EDX analytical techniques to particulate matter samples. EPA No. 600/R-02/070. Washington, D.C.: U. S. EPA.

Zhang, Y. 2004. Indoor Air Quality Engineering. Boca Raton, Fla.: CRC Press.

Zuskin, E., J. Mustajbegovic, E. N. Schachter, J. Kern, N. Rienzi, S. Goswami, Z. Marom, and S. Maayani. 1995. Respiratory function in poultry workers and pharmacologic characterization of poultry dust extract. Environ. Res. 70(1): 11-19. 